•研究报告・

\title{
海南岛周边海域造礁石珊瑚的群落结构及其分布
}

\author{
周红英 ${ }^{1,2}$ 姚雪梅 $1,2^{*}$ 黎 李 $^{3}$ 耿涛年 1,2 张 颖 1,2 \\ 1 (南海海洋资源利用国家重点实验室(海南大学), 海口 570228) \\ 2 (海南大学海洋学院，海口 570228) \\ 3 (海口市环境监察局, 海口 570125)
}

\begin{abstract}
摘要：基于形态学分类鉴定，并辅以分子标记，我们于2014-2015年调查分析了海南岛文昌云龙湾、万宁大洲岛、 儋州磷枪石岛、昌江沙鱼塘村、三亚鹿回头海域造礁石珊瑚的种类组成和分布。结果表明, 海南造礁石珊瑚的分 布较为广泛, 共鉴定出 10 科 17 属 55 种, 其中鹿角珊瑚科、滨珊瑚科和蜂巢珊瑚科为优势科。各海域造礁石珊瑚的 群落结构不同: 南部三亚鹿回头海域以分枝状鹿角珊瑚为主, 东部文昌云龙湾和万宁大洲岛海域分别以叶片状和 分枝状蓄薇珊瑚为主，而西部儋州磷枪石岛和昌江沙鱼塘村则分别以团块状滨珊瑚和蜂巢珊瑚为主。不同的地理 环境使海南岛周边海域珊瑚礁群落呈现出不同的演替型，具有明显的地域性分布特点。5个不同海域造礁石珊瑚的 覆盖率和多样性指数依次为: 三亚鹿回头 $>$ 文昌云龙湾 $>$ 昌江沙鱼塘村 $>$ 万宁大洲岛 $>$ 儋州磷枪石岛, 覆盖 率和多样性指数具有明显的正相关性。与2005-2010年的调查结果相比, 文昌云龙湾和万宁大洲岛保护区造礁石珊 瑚的覆盖率和多样性指数有所上升, 昌江沙鱼塘村和三亚鹿回头相对稳定, 儋州磷枪石岛则下降比较明显。死亡 率较高的是昌江沙鱼塘村邻近海域, 且多为最近半年内死亡。人类活动(保护性或破坏性)极大地影响着造礁石珊 瑚的多样性、覆盖率和死亡率。
\end{abstract}

关键词：海南; 造礁石珊瑚；群落结构; 分布

\section{Scleractinian coral community structure and distribution in the coastal waters surrounding Hainan Island}

\author{
Hongying Zhou ${ }^{1,2}$, Xuemei Yao ${ }^{1,2 *}$, Li Li ${ }^{3}$, Taonian Geng ${ }^{1,2}$, Ying Zhang ${ }^{1,2}$ \\ 1 State Key Laboratory of Marine Resource Utilization in South China Sea, Hainan University, Haikou 570228 \\ 2 College of Ocean, Hainan University, Haikou 570228 \\ 3 Department of Ecology and Environment Protection of Haikou, Haikou 570125
}

\begin{abstract}
Based on the classical morphological and molecular taxonomy, 55 scleractinian coral species, belonging to 17 genera and 10 families, were recorded in five different coastal areas (Yunlong Bay, Wenchang; Dazhou Island, Wanning; Linqiangshi Island, Danzhou; Shayutang Village, Changjiang; Luhuitou, Sanya) of Hainan between 2014 and 2015. The dominant families included Acroporidae, Poritadae and Faviidae. The community structures of coral reefs in the five coastal areas were different. In Sanya, located in the south of Hainan, branching Acropora corals dominated the coral communities. In Wenchang and Wanning, on the eastern coast of Hainan, the laminar and branching Montipora corals were the dominant groups. In contrast, the mass corals Poritadae and Faviidae dominated the western coast in Danzhou and Changjiang. Analyses of community structure indicated that different geographic environments regulated successional differences. Coverage rates and diversity index values had a positive correlation and were as follows: Sanya $>$ Wenchang $>$ Changjiang > Wanning > Danzhou. Compared with the data obtained between 2005 and 2010, the coverage rates and diversity index values increased in Wenchang and Wanning and were relatively stable in Sanya and Changjiang, but showed an obvious decrease in Danzhou. However, the death rate of scleractinian corals was the highest in Changjiang, and most of the corals died within the last six months of 2015. In our opinion, human
\end{abstract}

收稿日期: 2017-03-15; 接受日期: 2017-09-13

基金项目: 国家自然科学基金(31460555)和“中西部高校提升综合实力”资助项目

* 通讯作者 Author for correspondence. E-mail: yaoxuemei72@163.com 
activities (including both protective and destructive activities) greatly affected coverage rates, death rates and diversity of the coral reefs.

Key words: Hainan; scleractinian coral; community structure; distribution

珊瑚礁生态系统是地球上生物种类最丰富和 生产力最高的生态系统之一, 当前受人类活动干扰 和自然气候变化的影响, 珊瑚礁处于持续锐减的状 态(Spalding et al, 2001; Hughes et al, 2003; 牛文涛 等, 2010a)。我国以海南岛近岸和南海各群岛的珊瑚 礁分布最广、最有代表性(吕炳全等, 1984; 王丽荣 和赵焕庭, 2001)。近几十年来, 海南岛周边海域受 到人类活动的剧烈影响, 珊瑚礁群落组成和分布也 随之波动(吴钟解等, 2013)。

2005-2010年以来, 多位研究者在海南岛周边 局部海域进行了较详细的珊瑚种类多样性调查和 研究(赵美霞等, 2009; 杨晨等, 2011; 黄晖等, 2012; 吴钟解等, 2012), 但有关整个海南岛造礁石珊瑚资源 及其分布的调查报道依然较少(吴钟解等, 2013), 而 且对造礁石珊瑚群落结构与分布尚未进行深入研究。

由于珊瑚生长型多, 极易受生长环境影响而具 有很强的表型可塑性, 使得基于形态学的种属鉴定 存在很大难度以及争议(Bruno \& Edmunds, 1997; Todd, 2008; Arrigoni et al, 2012)。应用分子标记进行 分子学分类可解决传统分类中的一些难题(如不同 生态型的归类、杂交种的鉴定等), 且在造礁石珊瑚 的分类中已有一定的应用(Romano \& Palumbi, 1996; Fukami et al, 2004)。形态学和分子学鉴定相结合, 可以增加珊瑚种属鉴定的准确度。

本文选取海南东部(文昌云龙湾、万宁大洲岛)、 西部(儋州磷枪石岛、昌江沙鱼塘村)和南部(三亚鹿 回头)已有过珊瑚礁资源调查的海域, 再次进行种 类组成及分布调查。通过与过去的数据进行对比, 监测和跟踪海南岛周边海域造礁石珊瑚的健康状 况及对环境变动的响应。以经典形态学分类为主, 以分子标记为辅来确定造礁石珊瑚的种类组成, 通 过优势种、优势度、覆盖率及死亡率了解其群落结 构、分布和健康状况。

\section{1 材料与方法}

\section{1 采样地点}

2014年9月至2015年5月, 在海南岛周边共选取
5 个区域，即文昌云龙湾、万宁大洲岛、儋州磷枪石 岛、昌江沙鱼塘村、三亚鹿回头周边浅水海域(图1), 进行造礁石珊瑚群落结构及其分布特征的研究。其 中文昌云龙湾位于铜鼓岭自然保护区，万宁大洲岛 位于大洲岛海洋生态国家级自然保护区，三亚鹿回 头位于三亚珊瑚礁国家级自然保护区。

\section{2 调查方法}

在每个区域各设置 12 个调查站位，每个站位分 别在水下1-3 $\mathrm{m}$ 和3-6 $\mathrm{m}$ 处各设置1条调查断面, 每 条断面布设 1 条长 $50 \mathrm{~m}$ 的样带。首先由调查人员进 行搜索式调查, 如果没有造礁石珊瑚或者仅见到极 少量的石珊瑚分布, 则认为此站位的珊瑚覆盖率小 于 $1 \%$, 不进行定量调查(摄像样带法调查), 只做定 性描述(黄晖等, 2012)。如果某一站位的造礁石珊瑚 覆盖率大于 $1 \%$, 则进行种类组成分析，并调查其覆 盖率和死亡率。

\section{3 造礁石珊瑚的鉴定}

采用现场观测和拍摄，并采集部分珊瑚样品， 参考Veron (2000)和邹仁林(2001), 通过观察珊瑚群 体形态、珊瑚杯大小及间隔、共骨结构等来鉴定珊 瑚种类。

对于形态学特征难以辨别的珊瑚, 结合分子学 方法来鉴定。以珊瑚线粒体COI基因作为分子标尺,

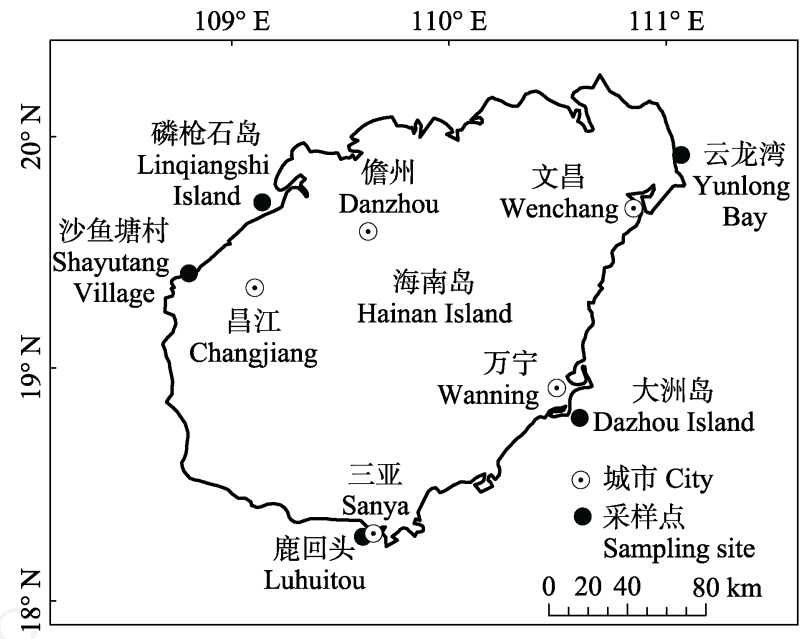

图1 海南岛周边海域造礁石珊瑚调查区域及采样地点

Fig. 1 Study areas and sampling sites of scleractinia corals in the coastal waters surrounding Hainan Island 
主要对鹿角珊瑚属(Acropora)、蓄薇珊瑚属(Montipora)、滨珊瑚属(Porites)和告丹珊瑚属(Pavona)进 行属级阶元的鉴定。采用宝生物工程(大连)有限公 司的 TaKaRa基因组DNA提取试剂盒提取珊瑚基因 组DNA。再以珊瑚线粒体COI基因的特异性引物 5'-TCA ACT AAT CAT AAA GAT ATT GGT ACG-3' (正向引物)和 $5^{\prime}$-TAA ACC TCT GGA TGC CCA AA-3' (反向引物)进行PCR扩增(Forsman et al, 2010)。反应 体系包括: 引物各 $1 \mu \mathrm{L}, \mathrm{DNA}$ 模板 $2 \mu \mathrm{L}, 2 \times \mathrm{PCR}$ Master Mix $12.5 \mu \mathrm{L}$ 。反应程序为: $95^{\circ} \mathrm{C}$ 预变性 $4 \mathrm{~min}$; $94^{\circ} \mathrm{C}$ 变性 $40 \mathrm{~s}, 56^{\circ} \mathrm{C}$ 退火 $30 \mathrm{~s}, 72^{\circ} \mathrm{C}$ 延伸 $40 \mathrm{~s}, 36$ 个循 环; $72^{\circ} \mathrm{C}$ 延伸 $10 \mathrm{~min}$ 。PCR产物切胶回收、纯化、测 序。把测得序列提交至GenBank比对, 确认其分类 地位, 可将样品分类至属。

\section{4 多样性指数、均匀度指数、覆盖率及死亡率的} 计算

Shannon-Wiener多样性指数(Shannon \& Weaver, 1949)的计算公式如下:

$$
H=-\sum_{i=1}^{s} p_{i} \log _{2} p_{i}
$$

式中, $S$ 代表物种数目, $P_{i}$ 指群落中第 $\mathrm{i}$ 个物种的总个 数占群落中所有物种总个数的比值。

Pielou均匀度指数的计算公式为(Belaoussoff et al, 2003): $E=H / \ln S$

珊瑚覆盖率 $=$ 活珊瑚覆盖率 + 死亡珊瑚覆 盖率

造礁石珊瑚死亡率 $=($ 造礁石珊瑚的死亡个数 $/$ 造礁石珊瑚的总个数) $\times 100 \%$

优势度的计算是优势种(属)生物量占调查样带 中总造礁石珊瑚生物量的比例。

造礁石珊瑚的死亡时间通过其单体来判断: 死 亡1个月内单体骨骼呈白色、完整清晰; 死亡半年内 单体被小型藻类或薄层沉积物覆盖; 死亡 $1-2$ 年之 内单体结构轻微腐蚀, 但仍能将其分类至属 (吴钟 解等, 2013)。

\section{2 结果}

2.1 海南造礁石珊瑚的主要种类、优势种及群落结构

本次调查共发现海南岛周边海域造礁石珊瑚 10 科 17 属 55 种, 包括鹿角珊瑚科、滨珊瑚科、蜂巢 珊瑚科、枇杷珊瑚科、木珊瑚科、杯形珊瑚科、菌 珊瑚科、丁香珊瑚科等。
对比2005-2010年的调查结果(赵美霞等, 2009; 牛文涛等, 2010b; 杨晨等, 2011; 黄晖等, 2012; 吴 钟解等, 2012), 海南岛周边海域造礁石珊瑚群落的 种类组成及近年来的变动状况如附录 1 所示。整体 来看, 造礁石珊瑚种类数下降最明显的为儋州磷枪 石岛, 相对稳定的为三亚鹿回头和昌江沙鱼塘村, 文昌云龙湾海域石珊瑚的多样性有所增加, 而万宁 大洲岛的明显增加。造礁石珊瑚数量下降最明显的 是鹿角珊瑚属, 如美丽鹿角珊瑚(Acropora formosa) 和佳丽鹿角珊瑚(A. pulchra)在 5 个调查区域都没有 发现。

对各站点造礁石珊瑚优势种属组成的分析发现 (表1): 文昌云龙湾造礁石珊瑚群落以叶片状蓄薇珊 瑚为主, 其次为分枝状的蓄薇珊瑚、鹿角珊瑚及皮 壳块状的蓄薇珊瑚; 万宁大洲岛的造礁石珊瑚群落 则以分枝状蓄微珊瑚为主，其次为分枝状鹿角珊瑚; 儋州磷枪石岛以大型团块状滨珊瑚和蜂巢珊瑚为 主, 其次为分枝状鹿角珊瑚; 昌江沙鱼塘村以团块 状蜂巢珊瑚为主, 其次为分枝状鹿角珊瑚; 三亚鹿 回头的造礁石珊瑚群落以分枝状鹿角珊瑚为主, 其 次为分枝状蓄薇珊瑚。

各海域的珊瑚种类组成和优势种变化最大的 是万宁大洲岛保护区，与2008-2009年(吴钟解等, 2012)的调查结果进行比对发现, 造礁石珊瑚优势 种在原有以块状珊瑚: 澄黄滨珊瑚(Porites lutea)、 二异角孔珊瑚(Goniopora duofasciata)、精巧扁脑珊 瑚(Platygyra daedalea)为主的基础上, 增加了一些 分枝状的珊瑚种类: 指状蓄薇珊瑚(Montipora digitata)、脆蓄薇珊瑚(Montipora fragilis)、伞房鹿角珊 瑚(Acropora corymbosa) 等。优势种从团块状澄黄滨 珊瑚为主转变为以分枝状的指状菩薇珊瑚与脆蓄 薇珊瑚为主, 且蓄薇珊瑚属的优势度高达 $73.3 \%$ 。

\section{2 海南造礁石珊瑚群落的多样性指数}

5 个海域的造礁石珊瑚多样性指数为三亚鹿回 头 $>$ 文昌云龙湾 $>$ 昌江沙鱼塘村 $>$ 万宁大洲岛 $>$ 儋州磷枪石岛, 但均匀度则是三亚鹿回头 $>$ 昌江 沙鱼塘村 > 文昌云龙湾 > 儋州磷枪石岛 $>$ 万宁 大洲岛(表2)。

\section{3 海南岛造礁石珊瑚的群落覆盖率和死亡率}

5 个调查区域造礁石珊瑚的覆盖率都比较高, 其中, 三亚鹿回头最高 $(40.2 \%)$, 文昌云龙湾 $(38 \%)$ 、 
表1 海南岛5个海域造礁石珊瑚的优势种属组成

Table 1 The dominant species of scleractinia in the five coastal waters surrounding Hainan Island

\begin{tabular}{|c|c|c|c|c|}
\hline 地点 Location & 优势属 Dominant genus & 优势种 Dominant species & $\begin{array}{l}\text { 种优势度 } \\
\text { Dominance of species (\%) }\end{array}$ & $\begin{array}{l}\text { 属优势度 } \\
\text { Dominance of genus (\%) }\end{array}$ \\
\hline \multirow{6}{*}{$\begin{array}{l}\text { 文昌云龙湾 } \\
\text { Yunlong Bay, } \\
\text { Wenchang }\end{array}$} & \multirow[t]{4}{*}{ 菩薇珊瑚属 Montipora } & 叶状菩薇珊瑚 $M$. foliosa & 35 & \multirow[t]{4}{*}{74} \\
\hline & & 平展蓄薇珊瑚 M. solanderi & 15 & \\
\hline & & 截顶蓄薇珊瑚 M. truncata & 6 & \\
\hline & & 浅窝菩薇珊瑚 $M$. foveolata & 6 & \\
\hline & \multirow[t]{2}{*}{ 鹿角珊瑚属 Acropora } & 细枝鹿角珊瑚 A. nana & 10 & \multirow[t]{2}{*}{14.5} \\
\hline & & 宽片鹿角珊瑚 A. lutkeni & 4 & \\
\hline \multirow{5}{*}{$\begin{array}{l}\text { 万宁大洲岛 } \\
\text { Dazhou Island, } \\
\text { Wanning }\end{array}$} & \multirow[t]{2}{*}{ 蓄薇珊瑚属 Montipora } & 指状蓄薇珊瑚 $M$. digitata & 49.2 & \multirow[t]{2}{*}{73.3} \\
\hline & & 脆蓄微珊瑚 $M$. fragilis & 23.5 & \\
\hline & 鹿角珊瑚属 Acropora & 伞房鹿角珊瑚 A. corymbosa & 2.7 & 3.1 \\
\hline & 蜂巢珊瑚属 Favia & 帛琉蜂巢珊瑚 F. palauensis & 2.4 & 6 \\
\hline & 扁脑珊瑚属 Platygyra & 精巧扁脑珊瑚 P. daedalea & 2.6 & 4 \\
\hline \multirow{5}{*}{$\begin{array}{l}\text { 儋州磷枪石岛 } \\
\text { Linqiangshi Island, } \\
\text { Danzhou }\end{array}$} & 滨珊瑚属 Porites & 澄黄滨珊瑚 P. lutea & 43.4 & \multirow[t]{2}{*}{61.8} \\
\hline & & 普哥滨珊瑚 P. pukoensis & 18.0 & \\
\hline & 蜂巢珊瑚属 Favia & 标准蜂巢珊瑚 F. speciosa & 12.7 & 16 \\
\hline & 菊花珊瑚属 Goniastrea & 粗糙菊花珊瑚 G. aspera & 5.3 & 10 \\
\hline & 鹿角珊瑚属 Acropora & 多孔鹿角珊瑚 A. millepora & 10.4 & 12 \\
\hline \multirow{5}{*}{$\begin{array}{l}\text { 昌江沙鱼塘村 } \\
\text { Shayutang Village, } \\
\text { Changjiang }\end{array}$} & 蜂巢珊瑚属 Favia & 标准蜂巢珊瑚 F. speciosa & 24 & 35 \\
\hline & 角蜂巢珊瑚属 Favites & 五边角蜂巢珊瑚 F. pentagona & 8 & 12 \\
\hline & 扁脑珊瑚属 Platygyra & 交替扁脑珊瑚 P. crosslandi & 10 & 21 \\
\hline & 鹿角珊瑚属 Acropora & 多孔鹿角珊瑚 A. millepora & 8 & 8.5 \\
\hline & 蓄薇珊瑚属 Montipora & 截顶蔷薇珊瑚 M. truncata & 7 & 7.8 \\
\hline \multirow{5}{*}{$\begin{array}{l}\text { 三亚鹿回头 } \\
\text { Luhuitou, Sanya }\end{array}$} & \multirow[t]{4}{*}{ 鹿角珊瑚属 Acropora } & 伞房鹿角珊瑚 A. corymbosa & 10.2 & \multirow[t]{4}{*}{60.6} \\
\hline & & 松枝鹿角珊瑚 M. monasteriata & 11.3 & \\
\hline & & 多孔鹿角珊瑚 A. millepora & 10.8 & \\
\hline & & 鼻型鹿角珊瑚 A. nasuta & 7.8 & \\
\hline & 蓄薇珊瑚属 Montipora & 横错萻微珊瑚 M. gaimardi & 3.9 & 5.1 \\
\hline
\end{tabular}

表2 海南岛 5 个海域造礁石珊瑚群落的多样性指数

Table 2 Values of coral diversity indices in the five coastal waters surrounding Hainan Island

\begin{tabular}{|c|c|c|c|c|c|}
\hline 地点 Location & $\begin{array}{l}\text { 文昌云龙湾 } \\
\text { Yunlong Bay, } \\
\text { Wenchang }\end{array}$ & $\begin{array}{l}\text { 万宁大洲岛 } \\
\text { Dazhou Island, } \\
\text { Wanning }\end{array}$ & $\begin{array}{l}\text { 儋州磷枪石岛 } \\
\text { Linqiangshi Island, } \\
\text { Danzhou }\end{array}$ & $\begin{array}{l}\text { 昌江沙鱼塘村 } \\
\text { Shayutang Village, } \\
\text { Changjiang }\end{array}$ & $\begin{array}{l}\text { 三亚鹿回头 } \\
\text { Luhuitou, Sanya }\end{array}$ \\
\hline 种类数 Species number & 22 & 19 & 19 & 16 & 29 \\
\hline $\begin{array}{l}\text { Shannon-Wiener多样性指数 } \\
\text { Shannon-Wiener diversity index }\end{array}$ & 3.51 & 2.84 & 2.67 & 3.48 & 4.41 \\
\hline $\begin{array}{l}\text { Pielou均匀度指数 } \\
\text { Pielou evenness index }\end{array}$ & 2.62 & 2.26 & 2.39 & 2.83 & 3.02 \\
\hline
\end{tabular}

昌江沙鱼塘村(35\%)和万宁大洲岛(30\%)相对较高, 儋州磷枪石岛较低(25\%) (表3)。万宁大洲岛的调查 区域分为前港和后港，平均覆盖率为 $30 \%$ 。后港养 护区的珊瑚覆盖率达到 $60 \%$ 以上，而生活区则只有 $0.1 \%$; 前港因常年有流沙沉积，覆盖率低至3\%。昌 江沙鱼塘村造礁石珊瑚的死亡率最高 $(37.5 \%)$, 且 死亡时间多在 1 年以内，其次为文昌云龙湾 $(7.8 \%)$, 部分珊瑚由于养殖污水的排放出现病害或死亡, 而其他 3 个调查区域的死亡率相对较低，为3-5\%
(表3)。

文昌云龙湾靠近育苗厂污水排放口区域的珊 瑚出现发病(发粉、变色)及白化现象，捞出水后粘液 分泌少，而远离污水区的珊瑚一般色泽健康，产粘 液丰富。昌江沙鱼塘村近岸区大部分珊瑚已发黑或 死亡, 珊瑚孔内已被绿藻覆盖, 死亡时间在半年以 内，岸边有大量死亡的珊瑚骨骼及海绵，而深水区 珊瑚生长较好。三亚鹿回头的调查区域多选择3-10 m 水深, 珊瑚生长受人为影响少, 珊瑚几乎无白化, 
表3 海南岛 5 个海域造礁石珊瑚群落的覆盖率和死亡率

Table 3 The coverage and death rate of scleractinia in the five coastal waters surrounding Hainan Island

\begin{tabular}{|c|c|c|c|c|}
\hline 地点 Location & $\begin{array}{l}\text { 总覆盖率 } \\
\text { Coverage rate (\%) }\end{array}$ & $\begin{array}{l}\text { 活珊瑚覆盖率 } \\
\text { Coverage rate of live scleractina (\%) }\end{array}$ & $\begin{array}{l}\text { 死珊瑚覆盖率 } \\
\text { Coverage rate of dead scleractina (\%) }\end{array}$ & $\begin{array}{l}\text { 死亡率 } \\
\text { Death rate (\%) }\end{array}$ \\
\hline $\begin{array}{l}\text { 文昌云龙湾 } \\
\text { Yunlong Bay, Wenchang }\end{array}$ & 38 & 35 & 3.0 & 7.8 \\
\hline $\begin{array}{l}\text { 万宁大洲岛 } \\
\text { Dazhou Island, Wanning }\end{array}$ & 30 & 28.5 & 1.5 & 5 \\
\hline $\begin{array}{l}\text { 儋州磷枪石岛 } \\
\text { Linqiangshi Island, Danzhou }\end{array}$ & 25 & 23.7 & 1.3 & 5 \\
\hline $\begin{array}{l}\text { 昌江沙鱼塘村 } \\
\text { Shayutang Village, Changjiang }\end{array}$ & 35 & 21.9 & 13.1 & 37.5 \\
\hline 三亚鹿回头 & 40.2 & 39 & 1.2 & 3 \\
\hline
\end{tabular}

目前都较健康。儋州磷枪石岛和万宁大洲岛珊瑚较 健康, 白化少。

\section{3 讨论}

\section{1 群落结构差异分析}

本研究的采样地点分布在海南岛的东部、西部 和南部海域, 基本上可以代表海南岛周边海域造礁 石珊瑚的分布及种类。由于实验室分析增加了分子 鉴定方法，因此提高了珊瑚样本分类的准确性。5 个不同区域的造礁石珊瑚群落结构与优势种明显 不同, 呈现不同的演替型。海南岛周边海域的珊瑚 群落演替具有较明显的地域性。于登攀和邹仁林 (1996)在研究鹿回头的造礁石珊瑚群落演替过程中 的变化动态时发现, 群落演替初期以滨珊瑚和蜂巢 类珊瑚为主, 后期则以鹿角珊瑚科珊瑚为主。从大 的空间尺度来看, 三亚(鹿回头)群落结构以分枝状 鹿角珊瑚为主, 其种类组成最丰富, 处于群落演替 后期; 东部以叶片状(文昌云龙湾)或是分枝状珊瑚 (万宁大洲岛)为主, 为演替中期; 而西部以团块状 珊瑚为主 (儋州磷枪石岛; 昌江沙鱼塘村), 则处于 群落演替初期。

群落整体在不同环境梯度的物种多样性有着 特定的时空格局, 而决定这种格局的根本原因是群 落自身及生境条件的共同作用(于登攀和邹仁林, 1996)。三亚鹿回头位于海南岛南部海域, 其地理位 置决定了水温及珊瑚虫的补充量可能比东、西部海 域都更高(吴钟解等, 2013), 群落结构以分枝状鹿角 珊瑚为主的特点非常明显。邹仁林(2001)认为, 造礁 石珊瑚的分布呈由南向北逐渐递减的趋势与海水 温度由南向北逐渐递减的趋势是一致的。本研究也
再次证实了这个结论。将东西部与三亚的物种比较 后发现, 东西部的物种都可以在三亚珊瑚群落中找 到。故本文研究仍然支持西沙珊瑚在洋流作用下扩 散到海南岛南部(三亚), 再从南部三亚扩散到东部 和西部这个推断(王道儒等, 2011)。

东西部海域选取的站位尽管纬度相近, 但群落 结构及优势种却差异明显。东部以叶片状或是分枝 状珊瑚为主, 而西部以块状珊瑚为主。于登攀和邹 仁林(1995)提出, 大空间范围的珊瑚群落结构可表 现出由少数几种环境因素决定的规律性。王道儒等 (2011)对东西部悬浮泥沙的监测发现, 西部的泥沙 悬浮物 $(27.97 \mathrm{mg} / \mathrm{L})$ 明显地高于东部 $(18.39 \mathrm{mg} / \mathrm{L})$, 故认为这可能是导致西部珊瑚覆盖率低的主要原 因。本文推测东西部地理和地质差异所引起的洋 流、悬浮物及营养成分等诸多环境因素的变化, 是 导致东西部群落结构差异的重要原因之一。

与 2005-2010年的调查数据(赵美霞等, 2009; 牛文涛等, 2010b; 杨晨等, 2011; 黄晖等, 2012; 吴 钟解等, 2012)比较本研究发现, 除万宁大洲岛外, 海南其他海域的分枝状鹿角珊瑚的种类数下降最 为明显。赵美霞等(2011)认为三亚鹿回头优势类群 从分枝状向团块状转化是珊瑚礁退化的表现。这是 由于分枝状鹿角珊瑚对环境要求更加苛刻, 对环境 变动响应更快(黄晖等, 2012)。相对于生长速率较快 的分枝状珊瑚，团块状珊瑚更能适应环境的变化， 如水温升高、水体富营养化等(Schlöder \& D'Croz, 2004)。董志军等(2009)研究团块状盔形珊瑚和分枝 状多孔鹿角珊瑚对温度升高的响应时发现, 鹿角珊 瑚在温度升高时更易白化, 这也从侧面证实了鹿角 珊瑚对环境变化的耐受性和适应性较低。 


\section{2 多样性指数及覆盖率分析}

2005-2010年的调查结果显示，调查区域造礁 石珊瑚种类的多样性和覆盖率在过去都比较高(赵 美霞等, 2009; 牛文涛等, 2010b; 杨晨等, 2011; 黄 晖等, 2012; 吴钟解等, 2012)。本次调查发现不同地 区珊瑚礁多样性指数和覆盖率差别较大。

三亚鹿回头的多样性指数和总覆盖率都是最 高的，但是鹿角珊瑚和蓄薇珊瑚的种类都有所减 少。赵美霞等(2009)认为过度捕捞、炸鱼挖礁、大 规模养殖等人类活动是造成该处珊瑚礁衰退的主 要原因。而三亚珊瑚礁自然保护区的设立，总的来 说对近年来珊瑚礁的保护还是有效果的，如三亚的 活珊瑚覆盖率由 2007 年的 $23.38 \%$ (吴钟解等, 2013) 上升到2014年的39\%。

文昌为海南岛珊瑚礁分布面积最大的市，拥有 较为广阔的浅水海域, 岸礁发育好, 使该地区造礁 石珊瑚的生长与繁殖具有优势(周祖光, 2004)。造礁 石珊瑚的种类较多, 群落的复杂性较高, 整体而言 造礁石珊瑚群落发展较好, 故其多样性指数和总覆 盖率较高。而且, 在文昌云龙湾海域获得的蓄微珊 瑚的种类数较过去调查结果有所增加, 其原因可能 是由于之前一些种类未被准确鉴定, 而本研究中使 用的分子标记提高了对之前未记录种的鉴定水平。 但其活珊瑚覆盖率和死亡率明显受到周围养殖业 的影响，即有养殖排污地方的珊瑚有病害或发黑、

粘液分泌少或白化现象。

昌江沙鱼塘村的多样性指数和总覆盖率相对 而言也比较高, 虽然群落结构以团块状珊瑚为主, 但珊瑚的多样性指数并不比万宁大洲岛(分枝状为 主的群落结构)低。黄晖等(2012)的研究表明, 儋州 磷枪石岛(团块状珊瑚为主的群落结构)的多样性指 数在 2005 年的调查中已达 4.4 , 说明团块状结构也 可能存在多种形态。吴钟解等(2013)的调查结果显 示，昌江过去的活珊瑚覆盖率在 $25 \%$, 死珊瑚覆盖 率为 $2.63 \%$; 但本次调查发现其覆盖率虽然很高, 但死珊瑚覆盖率达到 $13.1 \%$, 死亡率(37.5\%)也是最 高的，且死亡时间在半年内。本调查选址起初在海 尾，但调查时发现该处活珊瑚数量锐减，后来改到 了昌江沙鱼塘村采样调查。昌江海尾核电厂2015年 开始试运行, 排放热水是否是引起珊瑚死亡的主要 原因, 还需要再结合水质指标的测定给出结论。

万宁大洲岛活珊瑚覆盖率有显著的提高, 从
2007年的19.34\% (吴钟解等，2013)上升到目前的 $28.5 \%$ 。群落中分枝状珊瑚取代团块状珊瑚成为优 势种, 说明珊瑚群落已经从低级向较高级演替。但 是此次调查的区域主要位于内湾, 分为前港和后 港。前港常受到流沙掩埋，珊瑚覆盖率低，而后港 的水又过浅，不超过 $3.5 \mathrm{~m}$ (此地水深是各调查点中 较浅的), 且常受到台风袭击，故可能有些种类的珊 瑚没有被记录到，这或许是其种类多样性在 5 个站 点中不是很高的原因。在浅水区明显地发现指状萻 薇珊瑚覆盖率很高(达49.2\%), 故其均匀度较低。

儋州磷枪石岛目前以团块状滨珊瑚为主。过去 报道的分枝状鹿角和蓄薇珊瑚的种类大为下降。黄 晖等(2012)认为过度捕捞、盗采珊瑚、水体污染和 海岸工程等人类活动是造成该区造礁石珊瑚的覆盖 率和种类多样性下降的最主要原因。

珊瑚群落的分布虽然有特定的时空格局，但其 演替过程常常会受到各种扰动。气候变化产生的风 暴、温度升高、海平面升高、酸化等可产生大规模 的扰动。而在大规模的环境扰动的间隔期中，病害、 珊瑚捕食者增多等干扰也会对其群落演替产生较 大的影响(Done, 1999), 而且多为人类相关活动引 起的。赵美霞等(2009)发现三亚海域并未因全球变 暖引起大规模白化，人类活动反而是对演替干扰的 主要因素。本次调查的海域也未发现由全球变暖引 起的大规模白化，但在人类活动频繁的地区造礁石 珊瑚的多样性指数和活珊瑚覆盖率却都会大大下 降，适应环境变动的珊瑚种类可能成为优势种; 而 在人类活动影响较小的地区, 各类珊瑚生长的环境 基本稳定，能有较多种类的珊瑚生长和繁殖。

调查中发现, 开采珊瑚作为建筑材料、盗采珊 瑚及旅游业的快速发展会严重破坏珊瑚礁资源的 多样性和完整性; 未处理的污水直接排入珊瑚礁 区、过度无序的渔业生产活动和落后的渔业生产方 式导致的海水富营养化，海岸工程建设中的爆破与 挖掘活动生成的悬浮物, 都会导致海水水质下降, 对珊瑚的生长和繁殖有着极大的影响。而设立自然 保护区的地方 (三亚、万宁、文昌)，其珊瑚种类的多 样性及覆盖率确实较 5 年前的调查数据有所提高。

\section{4 小结}

从海南周边 5 个典型海域选取的站位进行珊瑚 礁资源调查发现，其群落结构、多样性、覆盖率等 
有明显不同, 不仅反映了该生态系统所处的地理环 境差异, 也和人类活动有密切关系。虽然地域差异 引起的环境变化是推动珊瑚礁群落演替的主要因 素, 但是近年来, 造礁石珊瑚的群落演替也受到强 烈的人为干扰, 其干扰强度如果超过珊瑚礁生态系 统的承载能力, 就会引起珊瑚礁群落的退化, 如多 样性下降及优势种变化、覆盖率大规模下降。在珊 瑚礁群落发生退化的海域, 应将工业、旅游业、养 殖业、捕鱼业等对珊瑚礁有破坏性的产业, 控制在 合理的范围和强度内。同时在一些发育良好且有特 色的珊瑚礁区域, 积极设立保护区进行自然恢复并 开展人工修复。持续地监测珊瑚礁的群落动态变化 仍然是必要的, 同时也要强化环境因子调查, 以进 一步明晰珊瑚群落与环境响应的关系。

\section{参考文献}

Arrigoni R, Stefani F, Pichon M, Galli P, Benzoni F (2012) Molecular phylogeny of the robust clade (Faviidae, Mussidae, Merulinidae, and Pectiniidae): an Indian Ocean perspective. Molecular Phylogenetics and Evolution, 65, 183-193.

Belaoussoff S, Kevan PG, Murphy S, Swanton C (2003) Assessing tillage disturbance on assemblages of ground beetles (Coleoptera: Carabidae) by using a range of ecological indices. Biodiversity and Conservation, 12, 851-882.

Bruno JF, Edmunds PJ (1997) Clonal variation for phenotypic plasticity in the coral Madracis mirabilis. Ecology, 78, 2177-2190.

Done TJ (1999) Coral community adaptability to environmental change at the scales of regions, reefs and reef zones. American Zoologist, 39, 66-79.

Dong ZJ, Huang H, Huang LM, Li YC, Shi X (2009) Symbiotic algae in two scleractinian corals: molecular phylogeny and their response to elevated temperatures. Acta Oceanologica Sinica, 31, 141-148. (in Chinese with English abstract) [董志军, 黄晖, 黄良民, 李元超, 时翔 (2009) 两种 造礁石珊瑚共生藻分子系统分类及其对水温升高的响应 研究. 海洋学报, 31, 141-148.]

Forsman ZH, Concepcion GT, Haverkort RD, Shaw RW, Maragos JE, Toonen RJ (2010) Ecomorph or endangered coral? DNA and microstructure reveal Hawaiian species complexes: Montipora dilatata/flabellata/turgescens \& $M$. patula/verrilli. PLoS ONE, 5, e15021.

Fukami H, Budd AF, Paulay G, Solé-Cava A, Chen CA, Iwao K, Knowlton N (2004) Conventional taxonomy obscures deep divergence between Pacific and Atlantic corals. Nature, 427, 832-835.

Huang H, You F, Lian JS, Zhang CL, Yang JH, Li XB, Yuan T, Dong ZJ (2012) Composition and distribution of scleractinian coral in the northwest of Hainan Island. Marine
Sciences, 36, 64-74. (in Chinese with English abstract) [黄 晖, 尤丰, 练健生, 张成龙, 杨剑辉, 李秀保, 袁涛, 董志 军 (2012) 海南岛西北部海域珊瑚礁造礁石珊瑚种类组 成与分布. 海洋科学, 36, 64-74.]

Hughes TP, Baird AH, Bellwood DR, Card M, Connolly SR, Folke C, Grosberg R, Hoegh-Guldberg O, Jackson JBC, Kleypas J, Lough JM, Marshall P, Nyström M, Palumbi SR, Pandolfi JM, Rosen B, Roughgarden J (2003) Climate change, human impacts, and the resilience of coral reefs. Science, 301, 929-933.

Lü BQ, Wang GZ, Quan SQ (1984) The characteristic of fringing reefs of Hainan Island. Geographical Research, 3, 1-16. (in Chinese with English abstract) [吕炳全, 王国忠, 全松青 (1984) 海南岛珊瑚岸礁的特征. 地理研究, 3, $1-16$.

Niu WT, Xu XZ, Lin RC, Huang DY (2010a) Effects of sedimentation on coral reefs and reef organisms. Marine Science Bulletin, 29, 106-112. (in Chinese with English abstract) [牛文涛, 徐宪忠, 林荣澄, 黄丁勇 (2010a) 沉积物对珊 瑚礁及礁区生物的影响. 海洋通报, 29, 106-112.]

Niu WT, Zhang XX, Lin RC, Wang CS (2010b) Diversity and distribution of coral species along the Changjiang coastal waters, Hainan Province. Journal of Oceanography in Taiwan Strait, 29, 389-393. (in Chinese with English abstract) [牛文涛, 张潇娴, 林荣澄, 王初升 (2010b) 海南昌江沿 岸海域石珊瑚的物种多样性及其分布. 台湾海峡, 29 , 389-393.]

Romano SL, Palumbi SR (1996) Evolution of scleractinian corals inferred from molecular systematics. Science, 271, 640-642.

Schlöder C, D'Croz L (2004) Responses of massive and branching coral species to the combined effects of water temperature and nitrate enrichment. Journal of Experimental Marine Biology and Ecology, 313, 255-268.

Shannon EC, Weaver W (1949) The Mathematical Theory of Communication. Urbana University of Illinois Press, Illinois.

Spalding MD, Ravilious C, Creen EP (2001) World Atlas of Coral Reefs, pp. 9-28. University of California Press, Berkeley.

Todd PA (2008) Morphological plasticity in scleractinian corals. Biological Reviews, 83, 315-337.

Veron JEN (2000) Corals of the World. Australian Institute of Marine Science Press, Townsville.

Wang DR, Wang HJ, Li YC, Yang Y, Liang W (2011) Preliminary study of coral larvae supplementary source around Leizhou Peninsula. Journal of Tropical Oceanography, 30, 26-32. (in Chinese with English abstract) [王道儒, 王华接, 李元超, 杨毅, 梁文 (2011) 雷州半岛珊瑚幼虫补充来源 初步研究. 热带海洋学报, 30, 26-32.]

Wang LR, Zhao HT (2001) The general characteristics of the coral reef ecosystem. Chinese Journal of Ecology, 20, 41-45. (in Chinese with English abstract) [王丽荣, 赵焕庭 
(2001) 珊瑚礁生态系的一般特点. 生态学杂志, 20 , 41-45.]

Wu ZJ, Chen SQ, Chen M, Li YC, Wang Q, Wang DR (2013) Preliminary survey and analysis of the resources of hermatypic corals in Hainan Island. Transactions of Oceanology and Limnology, 35(2), 44-50. (in Chinese with English abstract) [吴钟解, 陈石泉, 陈敏, 李元超, 王茜, 王道儒 (2013) 海南岛造礁石珊瑚资源初步调查与分析. 海洋湖 沼通报, 35(2), 44-50.]

Wu ZJ, Li CP, Chen M, Zhang GX, Li YC (2012) Investigation of marine resources and the study of conservation strategies in Dazhou Island Ocean-ecology National Nature Reserves. Ocean Development and Management, 29, 97-100. (in Chinese) [吴钟解, 李成攀, 陈敏, 张光星, 李元超 (2012) 大 洲岛国家级自然保护区海洋资源调查及其管理保护机制 探讨. 海洋开发与管理, 29, 97-100.]

Yang C, Yang YH, Song PX, Li HW (2011) Diversity of coral species along the Yunlong Bay coastal waters in Longlou Town of Wenchang City. Journal of Hainan Normal University (Natural Science), 24, 201-203. (in Chinese with English abstract) [杨晨, 杨亚辉, 宋培学, 李洪武 (2011) 海 南省文昌市龙楼镇云龙湾石珊瑚的物种多样性调查. 海 南师范大学学报(自然科学版), 24, 201-203.]

Yu DP, Zou RL (1995) General situation, problems and prospects of studies on scleratinian coral community structure. Chinese Biodiversity, 3, 26-30. (in Chinese with English abstract) [于登攀, 邹仁林 (1995) 造礁石珊瑚群落结构 研究的概况、问题和前景. 生物多样性, 3, 26-30.]

Yu DP, Zou RL (1996) Current situation and dynamics of spe- cies diversity in hermatypic coral community on Luhuitou fringing reef. Acta Ecologica Sinica, 16, 559-564. (in Chinese with English abstract) [于登攀, 邹仁林 (1996) 鹿回 头造礁石珊瑚群落多样性的现状及动态. 生态学报, 16 , 559-564.]

Zhao MX, Yu KF, Zhang QM, Shi Q (2009) Evolution and its environmental significance of coral diversity on Luhuitou fringing reef, Sanya. Marine Environmental Science, 28, 125-130. (in Chinese with English abstract) [赵美霞, 余克 服, 张乔民, 施祺 (2009) 近50 a来三亚石珊瑚物种多样 性的演变特征及其环境意义。海洋环境科学, 28 , 125-130.]

Zhao MX, Yu KF, Zhang QM, Shi Q (2011) Evaluating the sustainability of coral reefs in Sanya of Hainan Island using marine ecological footprint. Journal of Tropical Oceanography, 30, 74-80. (in Chinese with English abstract) [赵美霞, 余克服, 张乔民, 施祺 (2011) 应用海洋生态足迹评价三 亚珊瑚礁资源的可持续利用. 热带海洋学报, 30, 74-80.]

Zhou ZG (2004) The research status and conservation strategy of coral reefs in Hainan. Ocean Development and Management, 21(6), 48-51. (in Chinese) [周祖光 (2004) 海南珊瑚 礁的现状与保护对策. 海洋开发与管理, 21(6), 48-51.]

Zou RL (2001) Fauna Sinica: Invertebrata Coelenterata, Anthozoa, Scleractinian, Hermatypic Coral. Science Press, Beijing. (in Chinese) [邹仁林 (2001) 中国动物志 腔肠动物门 珊 瑚虫纲 石珊瑚目 造礁石珊瑚. 科学出版社, 北京.]

(责任编委：徐奎栋 责任编辑：间文杰)

\section{附录 Supplementary Material}

\section{附录1 海南岛周边海域的造礁石珊瑚主要种类组成}

Appendix 1 List of main scleractinian coral species in the coastal waters surrounding Hainan Island http://www.biodiversity-science.net/fileup/PDF/2017079-1.pdf 
周红英, 姚雪梅, 黎李, 耿涛年, 张颖. 海南岛周边海域造礁石珊瑚的群落结构及其分布. 生物多样性, 2017, 25 (10): 1123-1130.

http://www.biodiversity-science.net/CN/10.17520/biods.2017079

\section{附录1 海南岛周边海域的造礁石珊瑚主要种类组成}

Appendix 1 List of main scleractinian coral species in the coastal waters surrounding Hainan Island

\begin{tabular}{|c|c|c|c|c|c|c|c|c|c|c|}
\hline \multirow{6}{*}{$\begin{array}{l}\text { 种名 } \\
\text { Species }\end{array}$} & \multicolumn{2}{|l|}{ 文昌云龙湾 } & \multicolumn{2}{|l|}{ 万宁大洲岛 } & \multicolumn{2}{|c|}{ 儋州磷枪石岛 } & \multicolumn{2}{|c|}{ 昌江沙鱼塘村 } & \multicolumn{2}{|l|}{ 三亚鹿回头 } \\
\hline & \multicolumn{2}{|l|}{ Yunlong Bay, } & \multicolumn{2}{|l|}{ Dazhou Island, } & \multicolumn{2}{|c|}{ Linqiangshi Island, } & \multicolumn{2}{|c|}{ Shayutang Village, } & \multicolumn{2}{|l|}{ Luhuitou, } \\
\hline & Wenchang & & Wanning & & Danzhou & & Changjiang & & Sanya & \\
\hline & 2010 & 本研究 & 2008-2009 & 本研究 & 2005 & 本研究 & 2009 & 本研究 & 2005-2006 & 本研究 \\
\hline & (杨晨等， & This & & This & (黄晖等， & This & & This & (赵美霞等， & This \\
\hline & 2011) & study & 2012) & study & 2012) & study & 等,2010b) & study & 2009) & study \\
\hline 宽片鹿角珊瑚 Acropora lutkeni & + & + & - & - & - & - & - & - & - & - \\
\hline 粗野鹿角珊瑚 Acropora humilis & + & + & - & - & + & + & + & - & + & - \\
\hline 细枝鹿角珊瑚 Acropora nana & - & + & - & - & - & - & - & - & - & - \\
\hline 强壮鹿角珊瑚 Acropora valida & - & + & - & - & - & - & - & - & + & + \\
\hline 伞房鹿角珊瑚 Acropora corymbosa & + & - & + & + & - & - & - & - & + & + \\
\hline 多孔鹿角珊瑚 Acropora millepora & + & - & - & - & + & + & + & + & + & + \\
\hline 鼻型鹿角珊瑚 Acropora nasuta & - & - & - & - & + & + & - & - & - & + \\
\hline 风信子鹿角珊瑚 Acropora hyacinthus & + & - & - & + & + & + & - & - & + & + \\
\hline 壮实鹿角珊瑚 Acropora robusta & - & - & - & - & + & + & - & - & + & - \\
\hline 霜鹿角珊瑚 Acropora pruinosa & - & - & - & - & - & - & + & + & - & + \\
\hline 佳丽鹿角珊瑚 Acropora pulchra & + & - & - & - & - & - & + & - & + & - \\
\hline 美丽鹿角珊瑚 Acropora formosa & + & - & - & - & - & - & + & - & + & - \\
\hline 松枝鹿角珊瑚 Acropora brueggemanni & - & - & - & - & - & - & - & - & + & + \\
\hline 狭片鹿角珊瑚 Acropora haimei & - & - & - & - & - & - & - & - & - & + \\
\hline 谷鹿角珊瑚 Acropora cerealis & - & - & - & - & - & - & - & - & - & + \\
\hline 叶状蓄薇珊瑚 Montipora foliosa & + & + & - & + & - & - & - & - & - & + \\
\hline 平展蓄薇珊瑚 Montipora solanderi & + & + & - & - & - & - & - & - & - & - \\
\hline 横错蓄薇珊瑚 Montipora gaimardi & - & + & - & - & + & + & - & - & - & + \\
\hline 截顶蓄薇珊瑚 Montipora truncata & - & + & - & + & - & - & - & - & - & - \\
\hline 浅窝蓄薇珊瑚 Montipora foveolata & - & + & - & - & - & - & - & - & - & - \\
\hline 繁锦蓄薇珊瑚 Montipora efflorescens & - & + & - & - & + & - & - & - & + & - \\
\hline 髦刺菩薇珊瑚 Montipora hispida & - & + & - & - & - & - & - & - & - & - \\
\hline 斑星蓄薇珊瑚 Montipora stellata & - & + & - & - & - & - & - & - & - & - \\
\hline 指状萻薇珊瑚 Montipora digitata & - & - & - & + & - & - & - & - & + & - \\
\hline 脆蓄薇珊瑚 Montipora fragilis & - & - & + & + & - & - & - & - & - & - \\
\hline 疑惑萻薇珊瑚 Montipora aenigmatica & - & - & - & + & - & - & - & - & - & - \\
\hline 膨胀蓄薇珊瑚 Montipora turgescens & - & - & - & - & + & - & - & - & + & - \\
\hline 单星萻薇珊瑚 Montipora monasteriata & - & - & - & - & + & - & - & - & - & + \\
\hline 易变牡丹珊瑚 Pavona varians & + & + & - & - & - & - & - & - & - & - \\
\hline 叶形牡丹珊瑚 Pavona frondifera & + & + & - & - & - & - & - & - & - & - \\
\hline 十字牡丹珊瑚 Pavona decussata & - & + & + & + & + & - & + & + & + & + \\
\hline 标准厚丝珊瑚 Pachyseris speciosa & + & + & - & - & + & - & - & - & + & - \\
\hline
\end{tabular}


周红英, 姚雪梅, 黎李, 耿涛年, 张颖. 海南岛周边海域造礁石珊瑚的群落结构及其分布. 生物多样性, 2017, 25 (10): 1123-1130.

http://www.biodiversity-science.net/CN/10.17520/biods.2017079

\begin{tabular}{|c|c|c|c|c|c|c|c|c|c|c|}
\hline 毗邻沙珊瑚 Psammocora contigua & + & + & - & - & - & - & - & - & + & - \\
\hline 澄黄滨珊瑚 Porites lutea & + & + & + & + & + & + & + & + & + & + \\
\hline 普哥滨珊瑚 Porites pukoensis & + & - & + & - & + & + & + & + & + & + \\
\hline 二异角孔珊瑚 Goniopora duofasciata & - & + & + & + & + & + & + & - & + & + \\
\hline 标准蜂巢珊瑚 Favia speciosa & + & + & + & + & + & + & + & + & + & + \\
\hline 帛琉蜂巢珊瑚 Favia palauensis & - & - & + & + & - & - & + & + & - & - \\
\hline 粗糙菊花珊瑚 Goniastrea aspera & - & - & - & - & + & + & - & - & + & + \\
\hline 梳状菊花珊瑚 Goniastrea pectinata & - & - & - & + & + & + & - & - & + & - \\
\hline 少片菊花珊瑚 Goniastrea yamanarii & - & - & - & - & + & + & - & - & - & - \\
\hline 网状菊花珊瑚 Goniastrea retiformis & - & & + & + & + & - & - & - & + & + \\
\hline 精巧扁脑珊瑚 Platygyra daedalea & - & - & - & + & + & + & - & - & + & + \\
\hline 肉质扁脑珊瑚 Platygyra carnosus & + & - & - & - & - & - & - & + & + & + \\
\hline 交替扁脑珊瑚 Platygyra crosslandi & - & - & - & - & + & - & - & + & + & + \\
\hline 弗利吉亚肠珊瑚 Leptoria phrygia & - & - & - & + & - & - & - & - & - & - \\
\hline 锯齿刺星珊瑚 Cyphastrea serailia & - & + & - & - & + & + & + & - & + & + \\
\hline 五边角蜂巢珊瑚 Favites pentagona & - & + & - & - & - & - & + & + & + & + \\
\hline 丛生盔形珊瑚 Gataxea fascicutaris & - & - & - & + & + & + & + & + & + & + \\
\hline 稀杯盔形珊瑚 Galaxea astreata & - & - & - & + & - & - & + & - & + & + \\
\hline 鹿角杯形珊瑚 Pocillopora damicornis & - & - & + & + & + & - & + & + & + & + \\
\hline 缨真叶珊瑚 Euphyllia fimbriata & - & - & - & - & - & + & - & + & + & - \\
\hline 皱折陀螺珊瑚 Turbinaria mesenterina & - & - & - & - & + & + & - & + & - & - \\
\hline 盾形陀螺珊瑚 Turbinaria peltata & + & - & - & - & - & + & - & + & + & + \\
\hline 壳形足柄珊瑚 Podabacia crustacea & - & - & - & - & + & - & - & + & + & + \\
\hline 总物种数 Total species number & 18 & 22 & 10 & 19 & 26 & 19 & 16 & 16 & 33 & 29 \\
\hline
\end{tabular}

参考文献

Huang H, You F, Lian JS, Zhang CL, Yang JH, Li XB, Yuan T, Dong ZJ (2012) Composition and distribution of scleractinian coral in the northwest of Hainan Island. Marine Sciences, 36, 64-74. (in Chinese with English abstract) [黄晖, 尤丰, 练健生, 张成龙, 杨剑辉, 李秀保, 袁涛, 董志军 (2012) 海南岛西北部海域珊瑚 礁造礁石珊瑚种类组成与分布. 海洋科学, 36, 64-74.]

Niu WT, Zhang XX, Lin RC, Wang CS (2010b) Diversity and distribution of coral species along the Changjiang coastal waters, Hainan Province. Journal of Oceanography in Taiwan Strait, 29, 389-393. (in Chinese with English abstract) [牛文涛, 张潚娴, 林荣澄, 王初升 (2010b) 海南昌江沿岸海域石珊瑚的物种多样性及 其分布. 台湾海峡, 29, 389-393.]

Wu ZJ, Li CP, Chen M, Zhang GX, Li YC (2012) Investigation of marine resources and the study of conservation strategies in Dazhou Island Ocean-ecology National Nature Reserves. Ocean Development and Management, 29, 97-100. (in Chinese) [吴钟解, 李成攀, 陈敏, 张光星, 李元超 (2012) 大洲岛国家级自然保护区海洋 资源调查及其管理保护机制探讨. 海洋开发与管理, 29, 97-100.]

Yang C, Yang YH, Song PX, Li HW (2011) Diversity of coral species along the Yunlong Bay coastal waters in Longlou Town of Wenchang City. Journal of Hainan Normal University (Natural Science), 24, 201-203. (in Chinese with English abstract) [杨晨, 杨亚辉, 宋培学, 李洪武 (2011) 海南省文昌市龙楼镇云龙湾石珊 瑚的物种多样性调查. 海南师范大学学报(自然科学版), 24, 201-203.]

Zhao MX, Yu KF, Zhang QM, Shi Q (2009) Evolution and its environmental significance of coral diversity on Luhuitou fringing reef, Sanya. Marine Environmental Science, 28, 125-130. (in Chinese with English abstract) [赵美霞, 余克服, 张乔民, 施祺 (2009) 近50 a 来三亚石珊瑚物种多样性的演变特征及其环境意义. 海 洋环境科学, 28, 125-130.] 